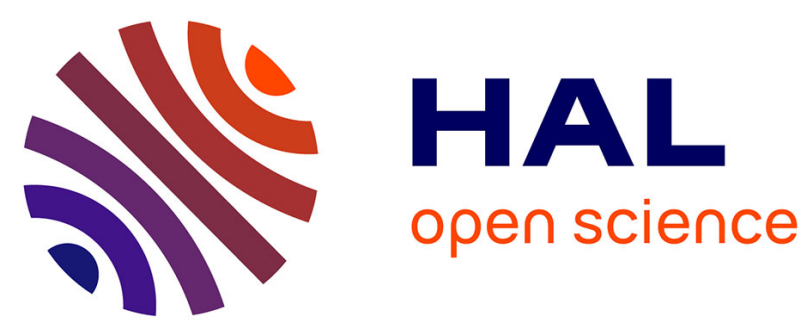

\title{
Contribution to the definition of a partial overlapping plastic strain rates domain for moderate loadings - application to tensile testing on metallic materials
}

\author{
Grégory Haugou, Eric Markiewicz, Jacky Fabis, Gérard Gary
}

\section{- To cite this version:}

Grégory Haugou, Eric Markiewicz, Jacky Fabis, Gérard Gary. Contribution to the definition of a partial overlapping plastic strain rates domain for moderate loadings - application to tensile testing on metallic materials. International Journal of Crashworthiness, 2004, 9 (2), pp.187-194. 10.1533/ijcr.2004.0278 . hal-00111426

\author{
HAL Id: hal-00111426 \\ https://hal.science/hal-00111426
}

Submitted on 12 Aug 2019

HAL is a multi-disciplinary open access archive for the deposit and dissemination of scientific research documents, whether they are published or not. The documents may come from teaching and research institutions in France or abroad, or from public or private research centers.
L'archive ouverte pluridisciplinaire HAL, est destinée au dépôt et à la diffusion de documents scientifiques de niveau recherche, publiés ou non, émanant des établissements d'enseignement et de recherche français ou étrangers, des laboratoires publics ou privés. 


\title{
Contribution to the definition of a partial overlapping plastic strain rates domain for moderate loadings - application to tensile testing on metallic materials
}

\author{
G Haugou $^{1,2}$, E Markiewicz ${ }^{2}$, J Fabis ${ }^{1}$ and G Gary ${ }^{3}$ \\ ${ }^{I}$ Office National d'Études et de Recherches Aérospatiales (ONERA/DMSE/RCS) 5, Boulevard Paul Painlevé, \\ 59045 Lille cedex, France \\ ${ }^{2}$ Laboratoire d'Automatique, de Mécanique et d'Informatique industrielles et Humaines, (LAMIH/DRC - UMR- \\ CNRS 8530), Université de Valenciennes et du Hainaut Cambrésis, Le Mont Houy, \\ Bâtiment Jonas 2, 59313 Valenciennes cedex 9, France eric.markiemicz@univ-valenciennes.fr \\ ${ }^{3}$ École Polytechnique de Palaiseau, Laboratoire de Mécanique des Solides UMR-CNRS 7649, 91128 Palaiseau, \\ France
}

\begin{abstract}
Generally, tensile testing on Hopkinson bars requires some particular considerations. Most of the specific devices, designed to hold tensile sheet specimens on the bars, involve the degradation of the pulses in particular case of no-direct tensile loadings. A tensile testing configuration for sheet specimens is proposed on the basis of classical split Hopkinson pressure bars (SHPB). Specimens holding is obtained with an epoxy adhesive and provides good measurements on sheet specimens.

A comparison is made for the same two metallic materials results extracted from literature and dynamic tensile tests performed with a high speed hydraulic machine and another split Hopkinson bars (SHPB) facility using hat-specimens. A partial overlapping domain in terms of plastic strain is shown at moderate strain rates from 200 to $400 \mathrm{~s}^{-1}$
\end{abstract}

Key words: Sheet specimens, moderate strain rates, no-direct tensile loading, Hopkinson bars device, overlapping domains, metallic materials.

\section{NOTATION}

$\varepsilon \quad$ plastic strain (.)

$\dot{\varepsilon} \quad$ plastic strain rate $\left(\mathrm{s}^{-1}\right)$

$\varepsilon_{\mathrm{eq}} \quad$ equivalent plastic strain (.)

$\gamma \quad$ plastic shear strain (.)

$\sigma_{\text {eq }} \quad$ equivalent plastic stress ( $\left.\mathrm{MPa}\right)$

$\sigma \quad$ conventional stress (MPa)

$\tau \quad$ duration time (ms)

\section{INTRODUCTION}

The identification of materials properties is based on the

Corresponding Author:

Prof Eric Markiewicz

Laboratoire d'Automatique, de Mécanique et d' Informatique Industrielles et Humaines

Université de Valenciennes du Hainaut Cambrésis

Le Mont-Houy Bat. Jonas 2

59313 Valenciennes cedex 9, France

Tel: +33 03-27-51-13-80 Fax: +33 03-27-51-13-17

Email: eric.markiewicz@univ-valenciennes.fr measurement of the evolution of the plastic stress/strain relations up to the fracture of the specimen over a large plastic strain rates range $[0.0001 ; 1000] \mathrm{s}^{-1}$. This range of strain and rates of strain is commonly observed during crash or impact of transportation frameworks. Consequently, thermoviscoplastic parameters of material laws, supplying FE models, have to be identified for the highest plastic strains through large experimental testing programmes. However, no universal facility allows to overlap this large range of strain and strain rates. The use of various testing facilities, bounded to partial strain rates ranges for a given plastic strain, is then necessary. Quasistatic machines, high-speed hydraulic machines and split Hopkinson bars are typically used as recurrent facilities. Technical limitations of high-speed hydraulic machines concern the exploitation capabilities of the collected raw data for a maximal plastic strain rate depending on the natural frequency of the assembly unit [1-3] and the closed loop control system. Moreover, the split Hopkinson bar technique is available for a limited time duration $\tau$ where the maximum strain is depending on the length and the 
speed of the striker $[4,5]$. Deconvolution techniques have been recently developed $[6,7]$ for lowest strain rates but are not yet commercially available. The paper proposes a tensile assembly unit composed of threaded sleeves for sheet specimens and placed between a split Hopkinson bars apparatus. The interest of the configuration lies in the minimisation of the impedance mismatch between the bars and the tensile assembly unit (see Fig. 3). The tensile loading is obtained indirectly by the impact of a long cylindrical projectile on the input bar in contact with the output bar. The dimensions of the bars and the location of the strain gauges are established with the help of a Lagrangian $\mathrm{x} / \mathrm{t}$ diagram [8]. The influence of the fixing ends is evaluated to quantify the impedance mismatch. A tensile tests programme on two metallic alloys is carried out at moderate strain rates and compared to others tests results for the same metallic alloys obtained on a high-speed hydraulic machine [9] and a SHPB apparatus using hat-specimens [10].

\section{TESTING TECHNIQUE}

\section{Description of the no-direct tensile testing configuration}

The aim of the ductile materials characterization is to have a maximum duration time of the output bar's loading. For instance, a typical low carbon steel admits an ultimate engineering plastic strain close to 0.4 before fracture. Consequently, for a constant strain rate of $200 \mathrm{~s}^{-1}$, the needed duration time $\tau$ is closed to $2 \mathrm{~ms}$. To ensure such duration time pulses, a $5 \mathrm{~m}$ long projectile and a $10 \mathrm{~m}$ long input bar to ensure a correct separation of the pulses without considering launch system limitations would be theoretically required. In order to ensure a maximum time duration of the incident pulse $\varepsilon_{\mathrm{I}}(\mathrm{t})$ for our set-up - required for ductile materials - the length of the projectile is closed to $1.1 \mathrm{~m}$.

For the corresponding duration time, thus $420 \mathrm{~s}^{-1}$, an engineering plastic strain of 0.1 is obtained for a plastic strain rate equal to $250 \mathrm{~s}^{-1}$ which is sufficient for the identification of behaviour laws parameters [11].

As represented in Figure 1, a Lagrangian $\mathrm{x} / \mathrm{t}$ diagram illustrates the three elastic pulses propagation along the bars [8]. Considering the length of the projectile, the output bar (OB) is $2.7 \mathrm{~m}$ long which is necessary to avoid any superposition of the first reflected pulse with the incident one. The initial elastic pulse (bolded line) propagates along the joined bars and through the assembly unit. After being reflected at the free face of the output bar, the initial compressive incident wave becomes a tensile incident wave. The specimens are then loaded and, $\mathrm{e}_{\mathrm{I}}$ being known, usual complementary elastic pulses are then obtained $\left(\varepsilon_{\mathrm{R}}, \varepsilon_{\mathrm{T}}\right)$. The location of the strain gauges was determined to avoid superposition of the reflected pulse $\varepsilon_{R}$ at the free ends with the incident pulse $\mathrm{e}_{\mathrm{I}}$ after its path along the two bars.

The no-direct tensile set-up is composed of two different bars lengths $\left(\mathrm{L}_{1}\right.$ and $\left.\mathrm{L}_{2}\right)$ and a cylindrical projectile named Lproj (see Fig. 2).

The two bars are made of $25 \mathrm{~mm}$ diameter maraging steel rods. The projectile is made of stainless steel with a $22.4 \mathrm{~mm}$ diameter. The Hopkinson bars are supported on 3 point-shapes spaced out $500 \mathrm{~mm}$. The initial pulse is obtained from the impact of a cylindrical projectile

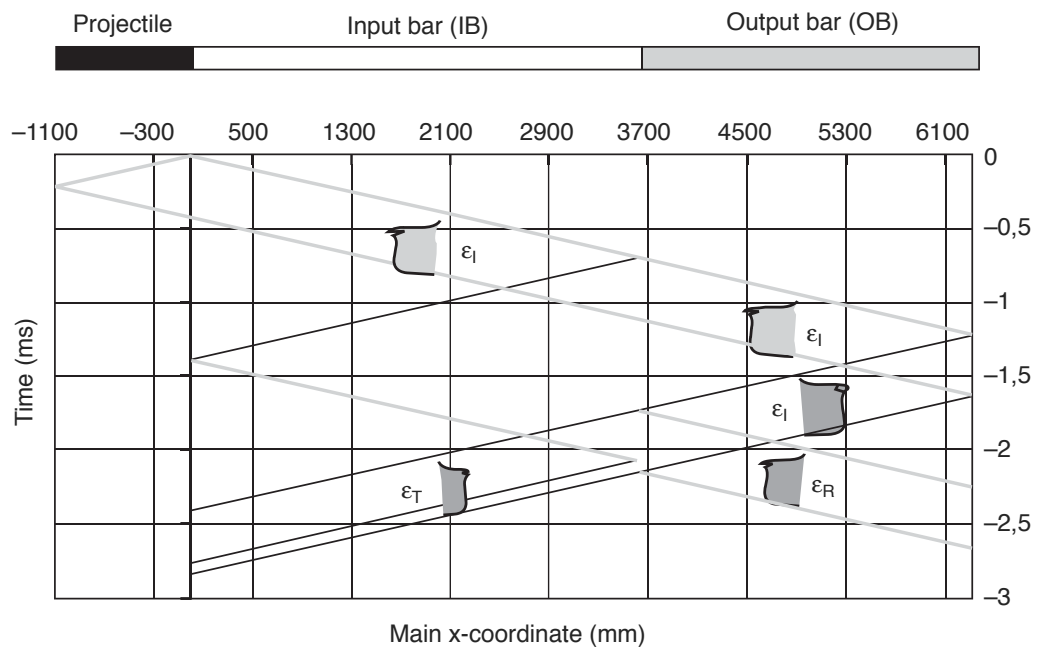

Figure 1 Lagrangian $\mathrm{x} / \mathrm{t}$ diagram of no-direct tensile configuration on Hopkinson bars.

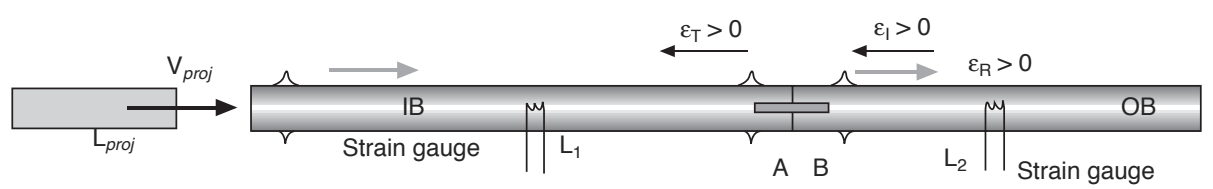

Figure 2 Schematic diagram of the no-direct tensile loading. 
launched by a gas gun. The mechanical properties of the set-up is summarized in Table 1 . The difference in diameter between the projectile and the bars induces a correction of the measured strain [12] in order to take into account the lack of energy brought back by the projectile.

Table 1 Specific dimensions of Hopkinson bars apparatus

\begin{tabular}{lccccc}
\hline & $\begin{array}{c}\mathrm{L} \\
(\mathrm{m})\end{array}$ & $\begin{array}{c}\varnothing \\
(\mathrm{mm})\end{array}$ & $\begin{array}{c}\text { Section } \\
\left(\mathrm{mm}^{2}\right)\end{array}$ & $\begin{array}{c}\text { Density } \rho \\
\left(\mathrm{kg} \cdot \mathrm{m}^{-3}\right)\end{array}$ & $\begin{array}{c}\text { Velocity } \\
C\left(\mathrm{~m}_{\mathrm{s}}{ }^{-1}\right)\end{array}$ \\
\hline $\begin{array}{l}\text { input bar } \\
\text { output bar }\end{array}$ & 3.6 & 25 & 491 & 8198 & 4627 \\
projectile & 1.7 & 25 & 491 & 8171 & 4599 \\
\hline
\end{tabular}

The three elastic pulses $\left(\varepsilon_{\mathrm{I}}(\mathrm{t}), \varepsilon_{\mathrm{T}}(\mathrm{t})\right.$ and $\left.\varepsilon_{\mathrm{R}}(\mathrm{t})\right)$ are recorded with a set of $3.2 \mathrm{~mm}$ strain gauges CEA-06125-UN-350 (ref. Measurement group) bonded on the Hopkinson bars with a cyanoacrylate adhesive. The output signals are obtained from a full-bridge into a Vishay 2310 amplifier. A 8-channel transient recorder (Nicolet MultiPro - sampling rate $1 \mathrm{MHz}$ ) is used to storage tests data (elastic pulses and signals from photo-diodes) afterwards. The length of the strain gauge allows a $145 \mathrm{kHz}$ bandwidth whereas a typical spectral signature of an impact using bars is closed to $50 \mathrm{kHz}$. The length of the cylindrical bars, the location of the strain gauges and the gauge dimensions of the specimen have been determined using classical relations $[12,13]$.

\section{TENSILE TESTS RESULTS}

\section{Material and specimens preparation}

Many modifications for the fixation of the specimens onto the bars are generally provided to ensure the holding of both undeformed parts on the specimen. For this, an adaptive assembly must be designed to produce a solicitation as pure as possible. The holding of the specimen is usually made with pin attachments (for plate specimens) or threads (for axi-symetric specimens). Those modifications may induce an impedance mismatch because of cross section variations in the bars $[8,14-16]$ or in the assembly [17-19]. Any section variation must be taken into account for the waves analysis [14]. For the proposed assembly unit, the two sleeves have been machined from the same steel alloy as the cylindrical bars by wire electroerosion. The choice of the principle is based on the minimization of the impedance mismatch [10, 15, 18, 20].

The speed of the striker bar has been limited to $10 \mathrm{~m} . \mathrm{s}^{-1}$ to avoid strain gauges deterioration. Moreover, the lowest speed is closed to $3 \mathrm{~m} \cdot \mathrm{s}^{-1}$ considering the limitations of the launching system. The gauge length for sheets specimen is chosen close to $11.3 \mathrm{~mm}$. It allows to reach the moderate strain rates domain $[200 ; 700] \mathrm{s}^{-1}$ for tensile tests. The full section is equal to four gauge sections of a specimen in order to obtain a significant amplitude of the transmitted signal and to avoid its amplification. The cross section of the sleeves is slightly decreased $(2 \%)$ by the four grooves tooled on the cylindrical sleeves surfaces for the positioning of the specimens (see Fig. 3). The gauge lengths of the specimens lies between 6.8 and $25 \mathrm{~mm}$ to have access to a theoretical strain rates range from 120 to $1400 \mathrm{~s}^{-1}$. For the lowest rate of strain, plastic strains close to 0.05 are measured. In the same way, the current set-up allows to reach plastic strains up to fracture for higher strain rates according to (1).

$$
\varepsilon=\dot{\varepsilon} \cdot \tau
$$

Figure 3 illustrates the progress of the 4-glued sheet specimens on the sleeves. An epoxy adhesive is laid on the adhesive areas of the specimens. Then, a pre-load is done at the free faces of the unit assembly to avoid any gap between the sleeves after the polymerisation of the epoxy adhesive (12 hours at room temperature).

Figure 4 shows the typical records on each bar using the no-direct tensile configuration on sheet specimens.

\section{XES steel and 2024 T3 aluminium alloy material characterization}

Tensile specimens have been machined by wire electroerosion from a cold-rolled sheet of XES steel $(W t \% \mathrm{C}=$ $0.05-\mathrm{Cr}<0.01-\mathrm{Cu}=0.013-\mathrm{Mn}=0.018-\mathrm{Al}=0.064-\mathrm{Ni}$ $=0.02)$ and $2024 \mathrm{~T} 3$ aluminium alloy $(W t \% \mathrm{Al}=93.5-\mathrm{Zn}$ $=0.22-\mathrm{Mg}=1.4-\mathrm{Cu}=4.2-\mathrm{Mn}=0.48-\mathrm{Fe}=0.17-\mathrm{Si}=$ 0.07). The XES steel specimens were machined from a $1.17 \mathrm{~mm}$ thick plate and oriented in the rolling direction. The 2024 T3 aluminium alloy specimens were machined from a $1 \mathrm{~mm}$ thick plate and oriented at $90^{\circ}$ regarding the rolling direction. Conventional quasi-static tests (QS) on the same geometry have been performed using an Instron universal testing machine (Model 1195) at a constant cross speed of $5 \mathrm{~mm} \cdot \mathrm{min}^{-1}$. Oscillations are observed for the highest plastic strain rate close to $420 \mathrm{~s}^{-1}$ and perturbs the stress vs. time calculation (see Fig. 5). The oscillations

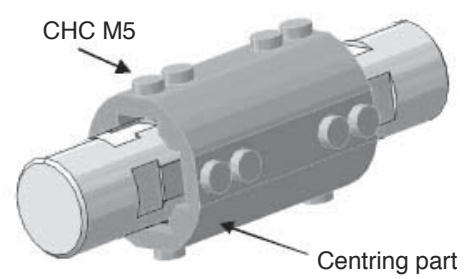

Figure 3 Progress of the 4-sheet metallic specimens on the cylindrical parts. 
No-direct tensile raw data on 4-glued XES steel sheet specimens using a Split Hopkinson bars set-up

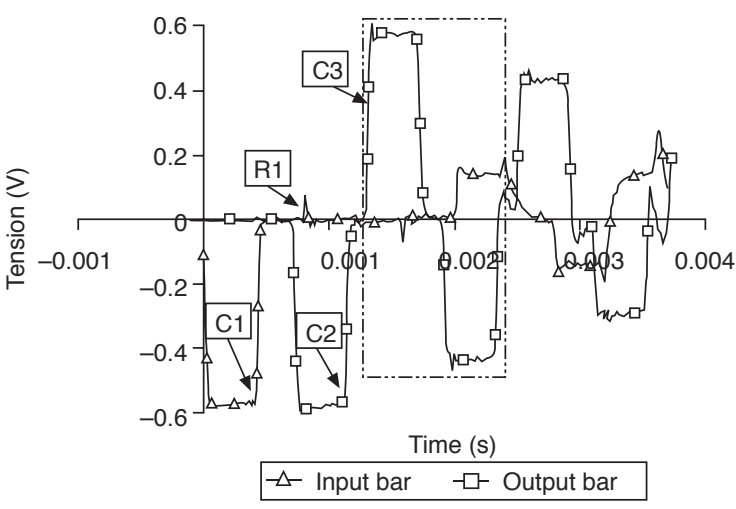

Figure 4 Raw data under no-direct tensile tests on Hopkinson bars device.

period corresponds to the run inside the sleeves of a partial reflected pulse of the incident wave. These interfaces may be responsible of the various reflections in the system [21]. So, the comparison is made considering filtered data (low frequency pass filtering) for impact tests using Hopkinson bars [22]. The input/output forces balance has been previously cheeked [21]. For further comparisons between the various dynamic facilities, the tests made with
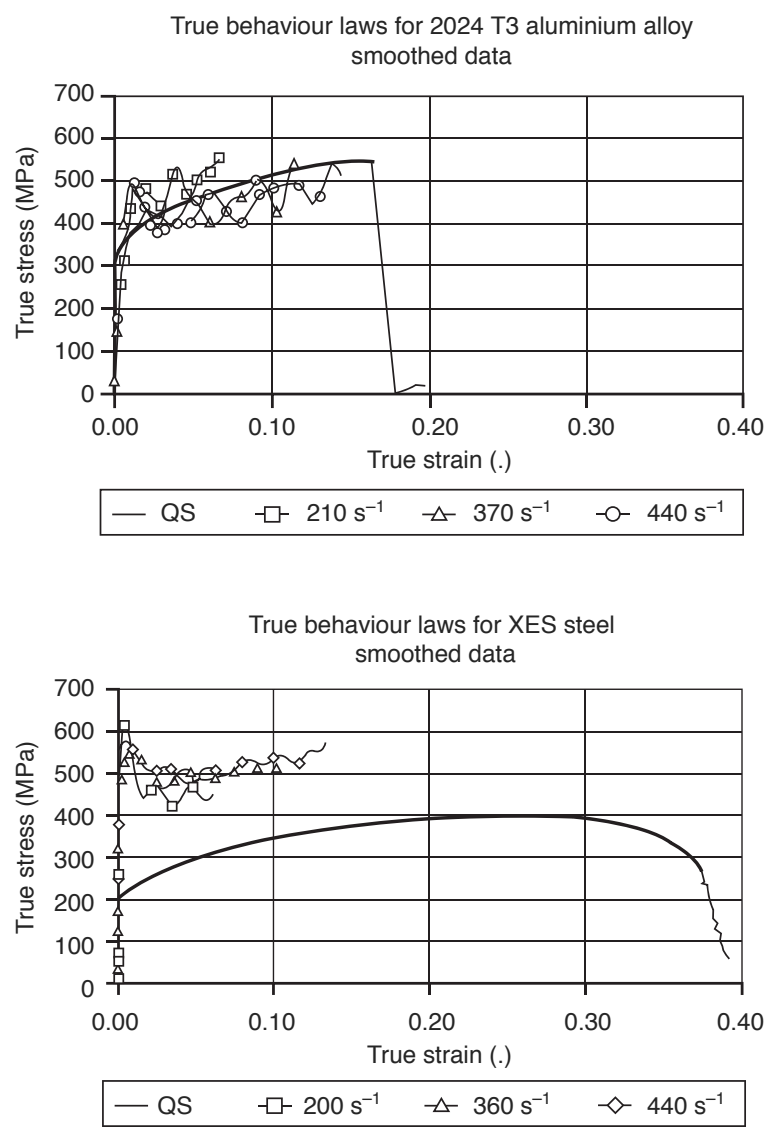

Figure 5 Behaviour laws at various strain rates - $2024 \mathrm{~T} 3$ aluminium and XES steel. the proposed configuration on the split Hopkinson bars apparatus are called "No-direct SHB".

\section{Comparison for different testing devices}

Two others testing facilities were used to complete the considered range in terms of strain and rates of strain. This approach is generally led to encompass a large strain rate domain [23-25]. A hydraulic Schenck machine uses a $50 \mathrm{kN}$ capacity linear actuator (see Fig. 6).

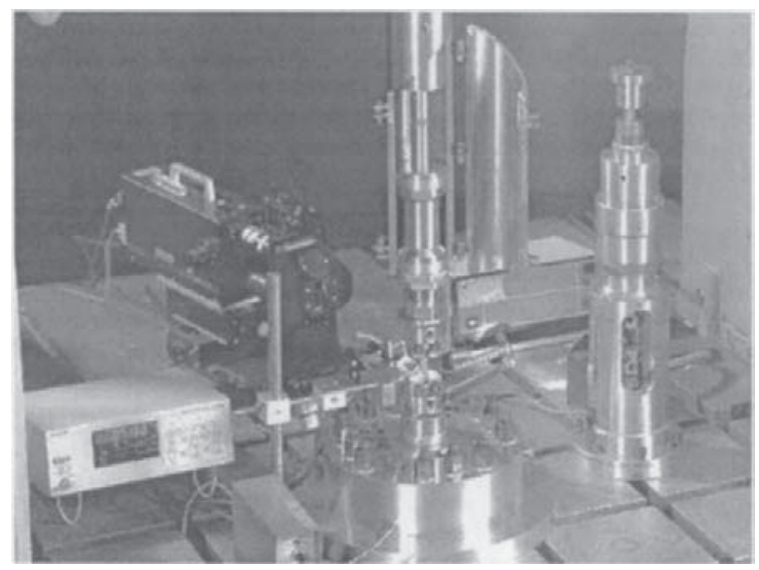

Figure 6 High-speed hydraulic testing machine (OneraLille Centre).

For the present tests, the servo system was programmed with a ramp function to provide a constant relative jack speed available up to $4 \mathrm{~m} . \mathrm{s}^{-1}$. Previous works have permitted to through out the natural frequency of the assembly. This kind of device is naturally subjected to mechanical vibrations depending on the weight of the added mass and the stiffness of the piezo-electric load cell $[1-3,9]$. The natural frequency of the testing set-up is closed to $8 \mathrm{kHz}$ which allows the access to theoretical plastic strain rates close to $200 \mathrm{~s}^{-1}$ according to material properties of the considered alloy $[9,26]$. The mechanical oscillations correspond to the natural frequency of the set-up due to the dynamic loading of the specimen and remains when fracture occurs [23]. For the tests on the hydraulic testing machine, an optical extensometer (Zimmer XH 200) was employed to measure higher plastic strains [26]. The gauge length L1 of the specimen was taken equal to $6.8 \mathrm{~mm}$ for a higher strain rates range [27, 28].

The second facility is composed of a SHPB apparatus described in details by Mouro [10] (see Fig. 7). In that configuration, a hat-specimen - machined by wire electroerosion and folded by a quasi static machine - is placed into a specific assembly unit between two cylindrical maraging bars (see Fig. 8).

The behaviour laws obtained using the high-speed hydraulic machine are named " $\mathrm{H}$ " and presented in details by Haugou [26]. In the same way, the tests results obtained with the second split Hopkinson pressure bars are named "SHPB-LMS". The results are plotted for the different testing devices and measurement systems (see Figs. 9 and 


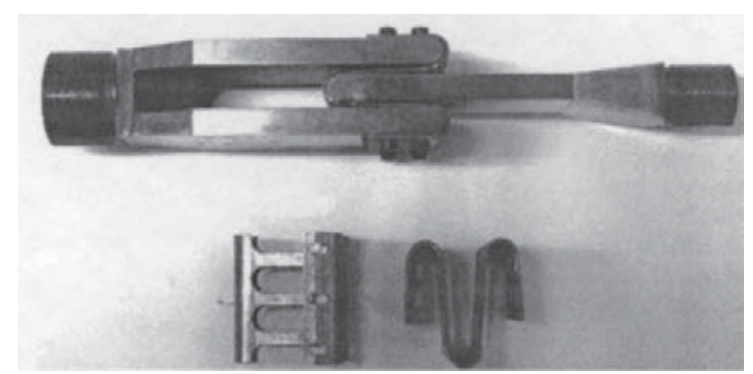

Figure 7 Special supports on classical SHPB (LMSPolytechnique).

10). The comparison is done for the XES low carbon steel at average strain rates of 230 and $520 \mathrm{~s}^{-1}$. In the same way, the comparison of the true relations is done for the $2024 \mathrm{~T} 3$ aluminium alloy and the same testing devices. It is verified that the considered alloy is not strain rate sensitive from quasi-static rates of strain to $500 \mathrm{~s}^{-1}$ (see Fig. 10).

\section{OVERLAPPING DOMAIN - DISCUSSION}

The comparison is made with results of previous tests programmes carried out for the $2024 \mathrm{~T} 3$ aluminium alloy $[11,27]$. Nicholas and Lawson [27] have performed shear tests from $10^{-4}$ to $4500 \mathrm{~s}^{-1}$ using three different testing devices (see Fig. 11). A quasi-static machine has covered the range of strain rates $\left[10^{-4} ; 10^{-2}\right] \mathrm{s}^{-1}$. A pneumatic machine has been used for the next domain from $10^{-2}$ to $100 \mathrm{~s}^{-1}$. Stress/strain relations from 500 to $4500 \mathrm{~s}^{-1}$ have been obtained with a torsional Hopkinson bars device. Plastic shear stress have been converted according to classical relations (2) and (3) based on the von Mises flow rules [29]. Langrand [11] has made quasi-static and dynamic tensile tests from 0.003 to $55 \mathrm{~s}^{-1}$ in order to identify the parameters of Johnson-Cook model for the 2024 T3 aluminium in order to supply FE riveted aeronautic frameworks models. The present comparison shows a good agreement with results obtained with the no-direct tensile configuration. The present testing process is then validated.

$$
\begin{aligned}
\sigma_{\mathrm{eq}} & =\sigma=\tau \cdot \sqrt{3} \\
\varepsilon_{\mathrm{eq}} & =\varepsilon=\frac{\gamma}{\sqrt{3}}
\end{aligned}
$$

For the XES steel, previous tests programmes have

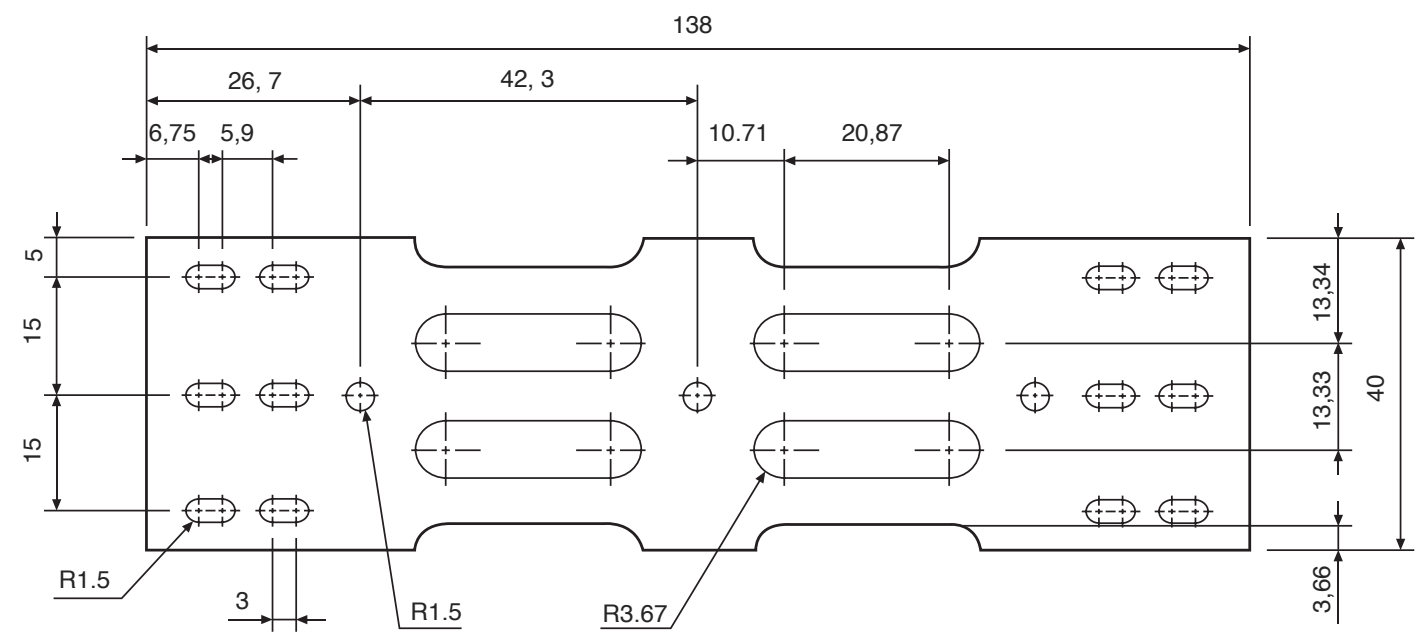

Figure 8 Geometry and dimensions of hat specimens (mm).
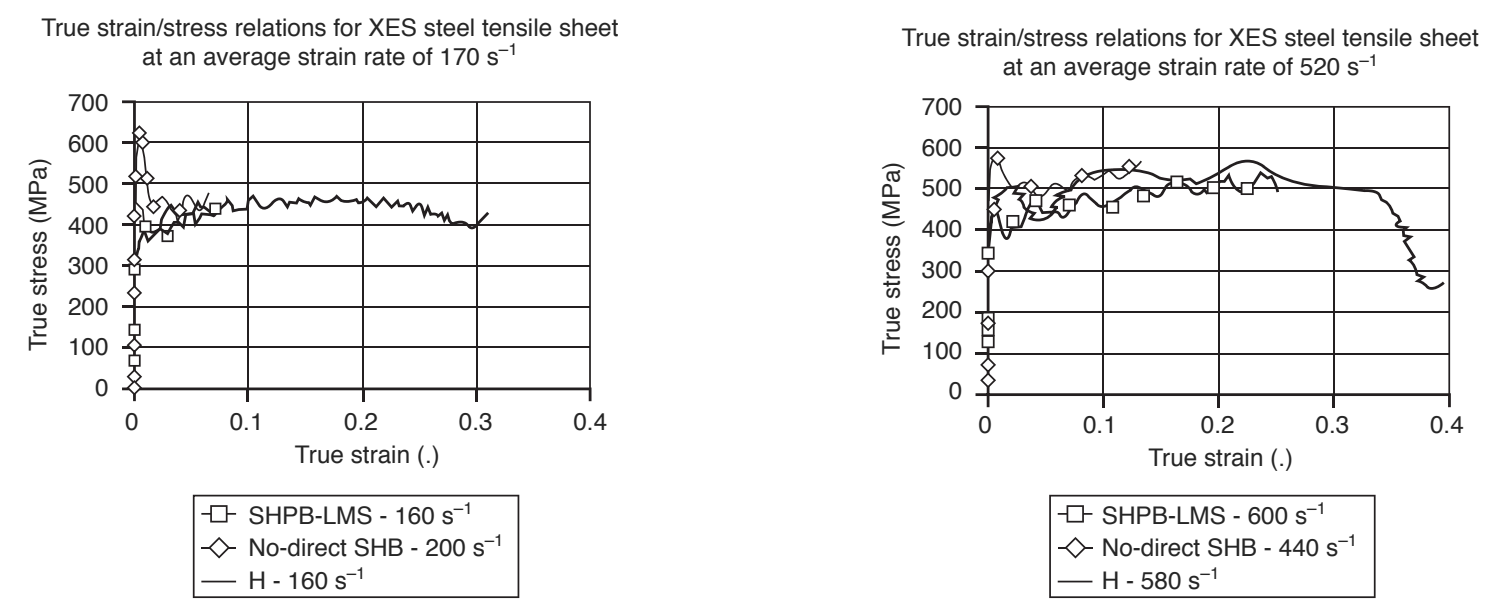

Figure 9 True relations of XES steel from different testing devices. 

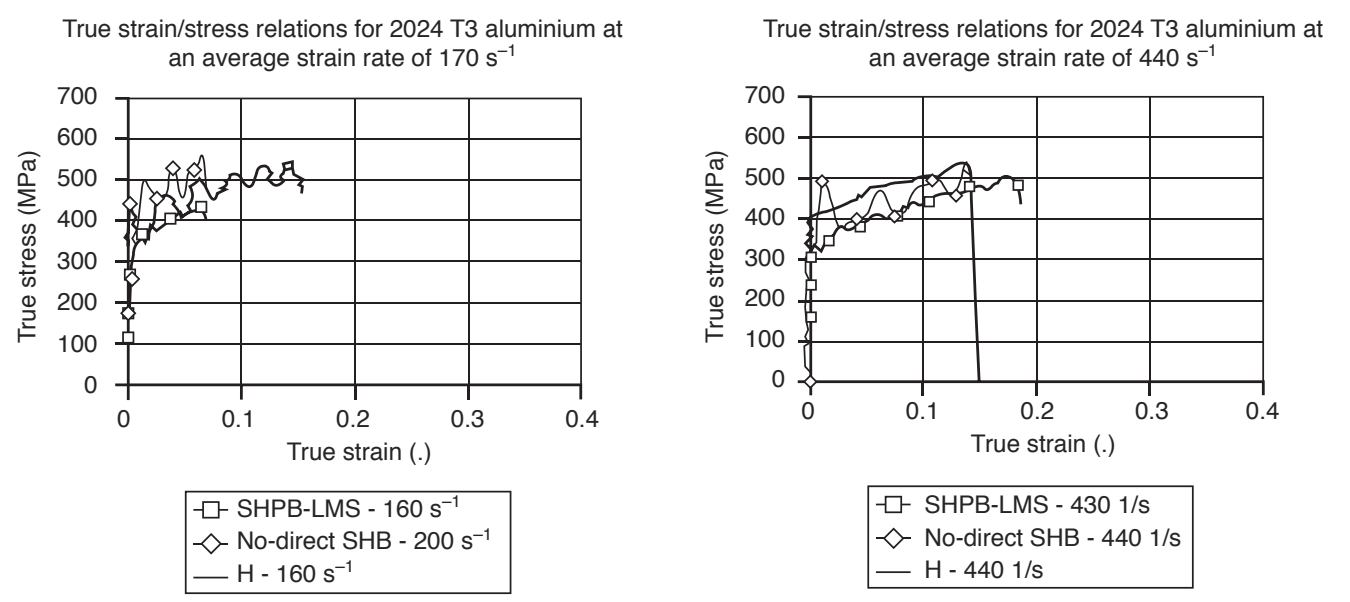

Figure 10 True relations of $2024 \mathrm{~T} 3$ aluminium alloy from different devices.

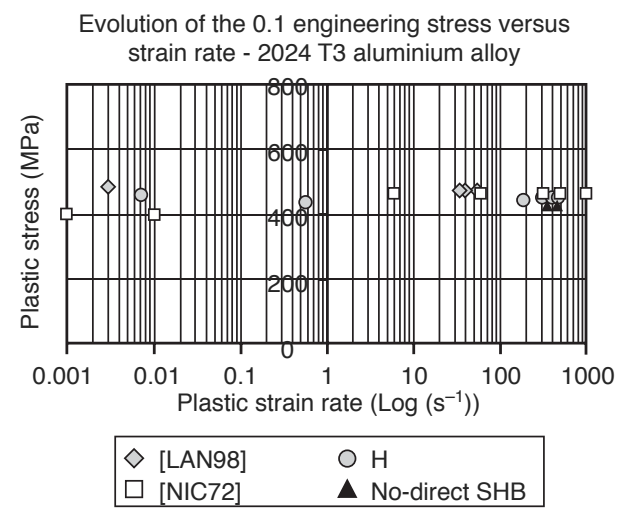

Figure 11 Comparison of the 0.1 plastic stress - 2024 T3 aluminium alloy.

been prospected under double shear [22], compression [5] and tensile [10] tests on sheet specimens within split Hopkinson bars devices. The domain of plastic strain rates was about 100 to $900 \mathrm{~s}^{-1}$. Materials are revealed to be strain rate sensitive for these various tests programs and the considered steel alloy, particularly for strain rates up to $100 \mathrm{~s}^{-1}$ (see Fig. 12). However, the use of different

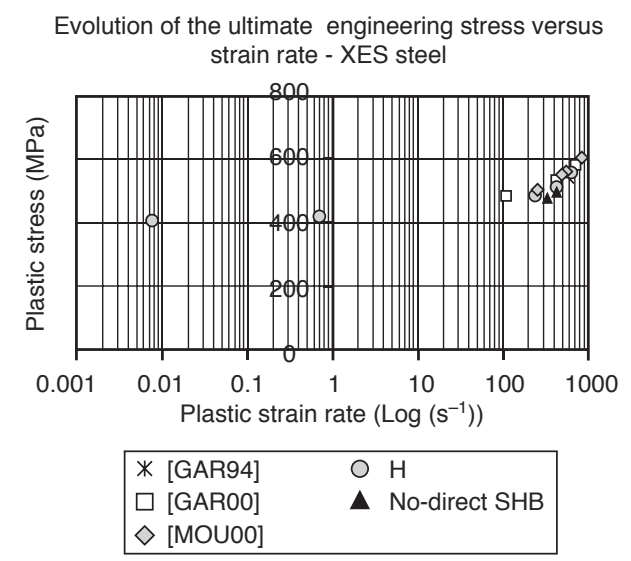

Figure 12 Comparison of the ultimate plastic stress XES steel. testing facilities raises the problem of the interpolation of the mechanical properties identified close to the technological limits of each device, such as oscillations on high-speed hydraulic machines and limited time duration on Hopkinson bars.

On the basis of the present tests programme, an overlapping domain is established for moderate rates of strain using plate specimens made of the same metallic alloys. The classical measurements devices have put into evidence a discontinuous plastic strain domain for moderate strain rates. This is especially clear for strain rate below 500 and $700 \mathrm{~s}^{-1}$ respectively for the $2024 \mathrm{~T} 3$ aluminium alloy and XES steel (see Figs. 13 and 14). So, for FE modelling of frameworks submitted to large plastic strains and plastic strain rates, an unknown domain remains to correctly identify parameters of viscoplastic laws.

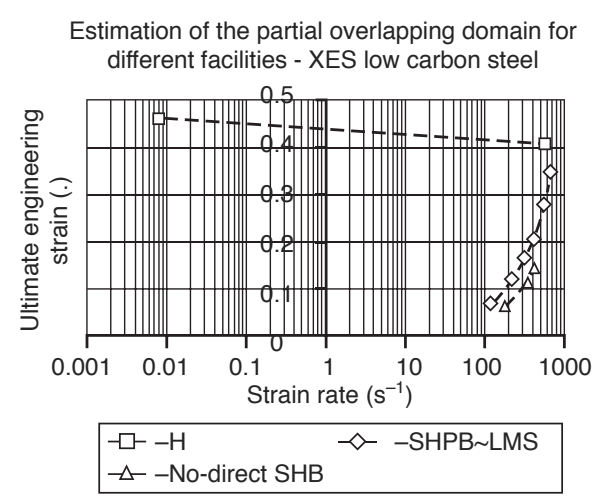

Figure 13 Overlapping domain for different testing facilities - XES steel.

\section{CONCLUSIONS}

The paper presents a no-direct tensile testing configuration based on glued sheet specimens on cylindrical sleeves. This assembly unit - containing 4-glued sheet specimens on its external surfaces without any others attachment tools - is threaded on a split Hopkinson bars device. Nevertheless, a problem of oscillations is still to be solved 


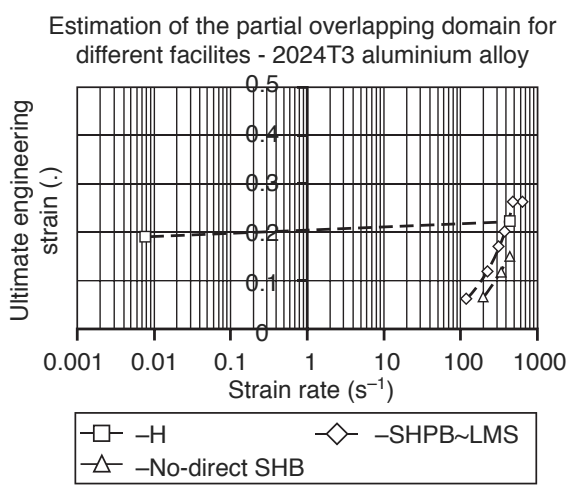

Figure 14 Overlapping domain for different testing facilities - $2024 \mathrm{~T} 3$ aluminium alloy.

to allow classical SHPB processing of the raw signals. Moreover, the gluing progress have to be controlled to avoid detachment for high strength materials (i.e. composites, HSS). This involves particular care for the design of the specimens and the related strain rates ranges.

The comparison of results obtained using the proposed no-direct tensile solicitation using classical Hopkinson bars apparatus with results from others techniques is shown for a common strain rates range from 200 up to $400 \mathrm{~s}^{-1}$. A high-speed hydraulic machine and a SHPB apparatus using hat-specimens are used for this purpose in order to have access to the domains of plastic rates of strain $[0.002$; $500] \mathrm{s}^{-1}$ and $[120 ; 700] \mathrm{s}^{-1}$, respectively. A good agreement is observed for the engineering stress/strain relations provided by the different tests facilities. A restricted overlapping domain has been underlined for the moderate plastic strain rates $[120 ; 500] \mathrm{s}^{-1}$ and plastic strains up to 0.1 for both metallic alloys (2024 T3 aluminium alloy and XES low carbon steel). This constitutes a limitation for FE analysis of crashworthiness behaviour in particular case where fracture is observed.

Then, direct measurements for the analysis of plastic strains using no-contact measurement devices are considered as optical extensometer techniques, high-speed camera for correlation analysis. In these conditions, a direct tensile configuration on $\mathrm{SHB}$ is required using the proposed assembly unit.

\section{ACKNOWLEDGMENTS}

This research was carried out with the financial support of the CNRS, ONERA-Lille Centre and the Conseil Régional du Nord/Pas de Calais. The present authors wish to thank especially A. Deudon, P. Mahelle and R. Barre for there contributions to the tests performed at Onera-Lille Centre and LMS-Polytechnique, respectively.

\section{REFERENCES}

1. Beguelin, P. "Approche expérimentale du comportement mécanique des polymères en sollicitation rapide”, Thèse de l'École Polytechnique Fédérale de Lausanne, 1996.
2. FABIS, J. "Caractérisation expérimentale de la loi de comportement d'un acier XES en dynamique”, Rapport Technique N97/63, 1997.

3. Rusinek, A, KlepaCzKo, J R. "Comportement viscoplastique des tôles en traction et cisaillement”, Matériaux et Techniques, 1999, 11/12, 41-52.

4. Rota, L. "Application de méthodes inverses au dépouillement de l'essai aux barres de Hopkinson", Thèse de l'École Polytechnique, 1997.

5. GARY, G, ZhaO, H. "Étude expérimentale du comportement dynamique des matériaux”, Mécanique et Industries, 2000, Vol. 1, 15-26.

6. Bussac, M N, Collet, P, Gary, G, Othman, R. “ $A n$ optimisation method for separating and rebuilding onedimensional dispersive maves from multi-point measurements Application to elastic or viscoelastic bars", Journal of the Mechanics and Physics of Solids, 2003, Vol. 50, 2, 321$350 \mathrm{w}$.

7. Отнman, R. “Extension du champ d'application du système des barres de Hopkinson aux essais à moyennes vitesses de déformation", Thèse de l'École Polytechnique de Palaiseau, 2002.

8. Nicholas, T. "Tensile testing of materials at high rates of strains”, Experimental Mechanics, 1980, Vol ${ }^{\circ} 21,177-186$.

9. Haugou, G, Fabis, J, Langrand, B, Deletombe, E, MaRKIEWICZ, E. "Iterative experimental/numerical procedure for improvement of dynamic experimental facilities", Conference on Solid Under Sock and Impact, Montreal, Canada, 2002, published in Witpress.

10. Mouro, P, Gary, G, Zhao, H. "Dynamic tensile testing of sheet metal”, Journal de Physique IV, 2000, Vol. ${ }^{\circ} 10,149-$ 154.

11. LangRAND, B. "Contribution à la caractérisation numérique et expérimentale d'assemblages structuraux rivetés sous sollicitation dynamique", Thèse de Doctorat de l'Université de Valenciennes, 1998.

12. GARY, G. "Some aspects of dynamic testing with mave-guides", New Experimental Methods in Material Dynamics and Impact, Warsaw 1, Poland, 2001, pp 179-222.

13. Zнао, H. “Analyse de l'essai aux barres d'HopkinsonApplication à la mesure du comportement dynamique des matériaux", Thèse de l'Ecole Nationale des Ponts et Chaussées, 1992.

14. Chocron-Benlolou, I S, Rodriguez, J, Martinez, M A, Sanchez-Galvez, V. "Dynamic tensile testing of aramid and polyethylene fiber composites", International Journal of Impact Engineering, 1997, Vol. 19, 2, 135-146.

15. Nguyen, C H Schindler, H J. “On spurious reflection maves in Hopkinson bar tensile tests using a collar", Journal de Physique IV, 1997, Vol. 7, 85-90.

16. Yuan, J M, Shim, V P W. "Tensile response of ductile $\alpha-$ titanium at moderately high strain rates", International Journal of Solids and Structures, 2002, Vol. 39, 213-224.

17. Kammerer, C. "Modélisation du comportement plan d'un $n$ verre E/polyester sous faibles et fortes vitesses de déformationApplication au cas de l'impact", Thèse de Doctorat de l'Université de Paris XIII, 1996.

18. Yокоуама, T, Isомото, T. "Impact tension testing of sheet metals for automobile structural uses", Proceedings of Asian Pacific Conference for Fracture and Strength, 1996, 795799.

19. RADFORD, D D, WorSWICK, M J. “The mechanical and 
constitutive behaviour of as-received and irradiated $\mathrm{Zr}-2.5 \mathrm{Nb}$ pressure tube material under high rates of tensile strain", Journal de Physique IV, 2000, 293-298.

20. Leblanc, M M Lassila, D H. "Dynamic tensile testing of sheet material using the Split Hopkinson bar technique", Experimental Techniques, 1993, Vol. 17, 37-42.

21. Haugou, G, Markiewicz, E, Fabis, J, Deletombe, E. "Nodirect tensile testing on Hopkinson bars apparatus : assessment of an original configuration by means of 4-glued sheet specimens", Journal of Testing and Evaluation, submitted, 2004.

22. Gary, G, Nowacki, W K. "Essai de cisaillement plan appliqué à des tôles minces”, Journal de Physique IV, 1994, Vol. 8, 6570 .

23. LindolHm, U S. "Effect of strain rate on yield strength, tensile strength and elongation of three aluminum alloys", Journal of Materials, 1971, Vol. 6, 119-133.

24. Nicholas, T. "Dynamic tensile testing of structural materials using a split Hopkinson bar apparatus”, Technical Report,
AFWAL TR 80-4053, 1980

25. Townsend, D, Park, N, Hammond, D, Devall, P. "Material Tests - Tensile properties of aluminium alloys $7010 T 651$ and AU4G over a range of strain rates", CRAHVI, Contract n ${ }^{\circ}$ G4RD-CT-2000-00395, Deliverable D 1.1.1, BAE Systems, 2002.

26. Haugou, G. "Moyens d'essais et de caractérisation de lois de comportement matérielles en dynamique moyennes vitesses", Thèse de Doctorat de l'Université de Valenciennes, 2003.

27. Nicholas, T, Lawson, J E. "On the determination of the mechanical properties of materials at high shear-strain rates", Journal of the Mechanics and Physics of Solids, 1972, Vol 20, 2, 57-64.

28. Hamouda, A M S, Hashmi, M S J. "Testing of composites materials at high rates of strain : advances and challenges", Journal of Materials Processing and Technology, 1998, Vol. $77,327-336$.

29. François, D, Pineau, A, Zaoui, A. “Comportement mécanique des matériaux”(2 volumes), Hermès Paris (1992-1993). 